\title{
When Less (Potential Demand) Is More (Revenue): Asymmetric Bidding Capacities in Divisible Good Auctions *
}

\author{
ORLY SADE ${ }^{1}$, CHARLES SCHNITZLEIN $^{2}$ and JAIME F. ZENDER ${ }^{3}$ \\ ${ }^{1}$ Jerusalem School of Business, Hebrew University of Jerusalem; ${ }^{2}$ College of Business \\ Administration, University of Central Florida; ${ }^{3}$ Leeds School of Business, University of Colorado \\ at Boulder
}

\begin{abstract}
We show that asymmetry in bidders' capacity constraints plays an important role in inhibiting collusion and promoting competitive outcomes in multi-unit auctions in which the final value of the good is common knowledge. This effect appears to be related to the increased difficulty of coordination when there are significant differences between bidders. Due to its impact on collusive outcomes, asymmetry in bidding capacities has a more powerful impact on the seller's revenue than does the auction type. Consistent with the finding in Sade et al. (2006) that the discriminatory auction is more susceptible to collusion than the uniform-price auction, asymmetry in capacity constraints has a greater impact in discriminatory auctions.
\end{abstract}

\section{Introduction}

A variety of goods are sold around the globe in multi-object or multi-unit (divisible good) auctions. Cellular phone licenses, energy, and mineral rights are all commonly sold via formalized auction procedures. There is also a widespread use of auctions in financial markets where IPOs, foreign exchange, and the treasury securities of many countries are being sold via auction. Despite their widespread usage, fundamental questions concerning even the standard multi-unit formats (the discriminatory and the uniform-price auctions) remain unanswered. Notably, a general revenue comparison of the standard types of divisible good auctions has yet to

$\star$ We thank Emmanuel Morales-Camargo, Ira Luria and Yelena Larkin for their excellent research assistance. We have benefited from comments by Yishay Yafeh, Eugene Kandel, Dan Levin, David Genesove, Eric Hughson, Steve Rock, Peter Bossaerts, David McAdams two anonymous referees, participants at the 2005 International Meeting of the Economic Science Association in Montreal, the 2006 winter meeting of the Econometric Society in Boston, and seminar participants at the University of Cincinnati, Hebrew University, Federal Reserve Bank of Atlanta, Tel-Aviv University, the University of Notre Dame, and Ben-Gurion University. Sade thanks the Israel Science Foundation (ISF 480/05) and the Krueger Center for Finance at the Hebrew University of Jerusalem for partial financial support. 
be achieved. Given the size of many of these markets small improvements in the price per unit can have a tremendous impact on actual revenue. ${ }^{1}$

An important issue that is intimately tied to a revenue comparison of the standard multi-unit formats, particularly when the auction participants interact repeatedly, is the susceptibility of these auctions to collusion or collusive-seeming behavior. ${ }^{2}$ Recent work in the theory of divisible good auctions shows that there exist non-cooperative equilibria under the uniform-price format that support collusive-seeming outcomes. ${ }^{3}$ While the discriminatory auction is not as susceptible to the strategies underlying the collusive-seeming outcomes, Friedman (1960) has argued that the discriminatory auction is more susceptible to outright collusion and suffers more from the winner's curse. Any theoretical comparison of the expected revenue generated in repeated uniform-price or discriminatory auctions will be determined in part by these forces.

We use an experimental auction setting in which the final value of the good is common knowledge and there is open communication between bidders to examine a characteristic of auction markets that is predicted to affect the bidders' ability to collude; asymmetry in capacity constraints. An asymmetry is imposed on the bidders by preventing some of the participating bidders from bidding for the entire quantity of the good offered for sale. This investigation was motivated by the observation that in government securities auctions there are often a wide variety of players. Bidders in these auctions are generally both large and small financial institutions. In some countries individuals are also allowed to participate in the primary auctions. These different types of bidders have significantly different capacities to purchase the offered securities and this difference has been predicted to affect their ability to collude. The industrial organization literature, for example, shows that asymmetries between agents will often limit the ability of the agents in a given market to collude. ${ }^{4}$ The experimental economics literature, studying cooperation in a variety of contexts, also documents that asymmetry in endowments reduces the level of cooperation. ${ }^{5}$ Finally, our experiment was also motivated by the experimental work on coordination that followed Schelling's (1960) initial work. ${ }^{6}$

The examination of multi-unit auctions has posed a challenge for researchers. The equilibrium strategies are complex, there commonly exist multiple equilibria

\footnotetext{
1 Garbade and Ingber (2005), for example, report that the U.S Treasury auctioned $\$ 3.42$ trillion worth of its securities in 2003 over 202 auctions.

2 Klemperer (2002) notes that: "The most important issues in auction design are the traditional concerns of competition policy - preventing collusive, predatory, and entry-deterring behavior".

3 See, for example, Wilson (1979), Back and Zender (1993), Ausubel and Cramton (1996) or Wang and Zender (2002) for theoretical results on strategic bidding in multi-unit auctions.

4 For a survey of the effects of capacity constraints on tacit collusion in oligopolistic industries see Rey (2003, pp. 114-115).

5 Ledyard (1995), in a survey of the experimental literature concerning public goods, states that the evidence suggests that asymmetry in endowments will affect cooperation among the participants.

6 For a survey of this literature see Crawford (1997). For a specific example of coordination with respect to auction entry decisions see Smith and Levin (2001).
} 
and the repeated nature of many of the auction markets of interest makes it difficult to analyze them theoretically. In addition, the difficulty of obtaining rich data sets for these markets makes empirical explorations difficult. An experimental study is, therefore, a natural direction in which to turn.

The main results of this study are that the introduction of asymmetry in the bidding capacities of the participants significantly reduced the amount of collusion and increased the revenue obtained by the seller. The increase in average revenue is shown to be the result of the reduction in collusive behavior. Friedman (1960) has argued that the discriminatory auction will be more susceptible to collusion than is the uniform-price auction (see Sade et al. (2006) for supporting experimental evidence) and consistent with this we find that the impact of the asymmetry is greatest in the discriminatory auction. It is noteworthy that an increase in average revenue is generated in both types of auctions despite the fact that the bidder asymmetry was obtained by reducing the total amount of potential demand.

Several papers have examined the issue of "collusive-seeming" strategies in the uniform-price auction. Goswami et al. (1996) show experimentally that communication may increase bidders' tendency to play collusive or collusive-looking strategies. Back and Zender (2001) develop a model showing that when the seller retains the right to reduce the supply of the good offered at auction after observing the bids the bidders' ability to inhibit competition is limited. McAdams (2005) shows that the seller retaining the right to increase supply ex post enhances competition while LiCalzi and Pavan (2005) show that the use of an increasing supply curve serves a similar purpose. Kremer and Nyborg (2002 and 2003) show that, when prices, quantities and bids are discrete, the underpricing resulting from collusive-looking strategies can be made arbitrarily small by choosing a sufficiently small price tick size and a sufficiently large quantity "tick". They also show how revenue may be improved by modifying the allocation rule.

Recent experimental work has shown that the discriminatory auction is more susceptible to outright collusion on the part of bidders playing a repeated game. Sade et al. (2006) (SSZ hereafter) demonstrate that in their experimental setting bidders do not play the standard collusive-seeming strategies in the uniform-price auction rather the greatest threat to the seller's revenue is the use of outright collusion on the part of the bidders. ${ }^{7}$

The focus of our paper is the effect of the budget constraint on divisible good auction outcomes. Pitchik and Schotter (1988) investigate experimentally the role of budget constraints in sequential auctions under perfect information. In their

\footnotetext{
7 In contrast, Abbink et al. (2004) report on an experiment in which they find higher revenues in a discriminatory auction than in a uniform-price auction. The auction setting in that paper is quite different from that used here. Most importantly their study uses a "multi-unit" design (allowing at most two bids, each for a single unit, per bidder) rather than a "divisible good" design as commonly used in Treasury auctions and in the present study. Further, while they do examine collusive, they set the supply of the good such that (at least) one bidder is guaranteed to receive no allocation, making it difficult for the bidders to sustain collusive agreements. Finally, while they use a common value environment, their setting includes uncertainty and asymmetric information.
} 
setting the goods are heterogeneous and are sold one at a time sequentially. Their setting is different than ours in many ways since in our experiment the auctioneer sells multiple (26) homogenous units to several bidders in the same auction. Yet, both papers find that the budget constraint affects bidding behavior. Different forces, however, appear to be at work across the two mechanisms. The intuition in the sequential auction mechanism for the effect of a capacity constraint on bidding behavior as described in Benoit and Krishna (2001) is that when multiple objects are sequentially auctioned in the presence of budget constraints, it is advantageous for a bidder to bid aggressively on one object with a view to raising the price paid by his rival and depleting his budget so that the second object may then be obtained at a lower price. The intuition for the difference in bidding behavior in the divisible good auction is that the asymmetry in budget constraints makes it harder for bidders to collude since they find it difficult to agree on how to divide the surplus.

Armantier and Sbaï (2003) also study divisible good auctions with asymmetric bidders. They develop a model that allows for agents who differ in terms of the precision of their private signals and their levels of risk aversion. Empirical tests, using data from French treasury auctions, provide evidence of asymmetries in the precision of their private information and in bidders' levels of risk aversion. The complexity of their model requires that they use numerical methods to find a solution. They are also unable to consider the repeated nature of the game despite the fact that the auctions tend to involve largely the same players auction after auction.

This paper is organized as follows. Section 2 describes the theoretical foundations of our experiment. In section 3 we describe the experimental design, and the empirical results are presented in section 4 . Section 5 contains concluding remarks. An appendix with the written instructions provided to the participants is available on line at the following URL: http://www.univie.ac.at/rof/papers/supplements/ Sade-Schnitzlein-Zender_Divisible Good Auctions_supplement.pdf.

\section{Theory}

In divisible good auctions bidders are able to submit multiple price quantity pairs (demand schedules) as bids. The submitted bid schedules are aggregated to form a downward sloping aggregate demand curve and the highest price at which aggregate demand equals or exceeds the supply is the stop-out price. Winning bids are those submitted at or above the stop-out price. In a uniform-price auction the same price (here, the stop-out price) is paid for all winning bids while in a discriminatory auction the bid price is paid for all winning bids.

In the present experiment we use an auction game in which $N=5$ bidders compete for $Q=26$ units of a good labeled a widget. In order to abstract from concerns over the winner's curse and concentrate on the strategic aspects of the auction, we ensure that it is common knowledge among the bidders that the aftermarket value of the widget (in Francs, the artificial currency of the experimental market) is $20 \mathrm{Fr}$. We use a discrete price and quantity grid in which the "step size" 
in both dimensions is 1 . In particular bids may be submitted as quantity orders at the 4 distinct prices contained in the set $\{17,18,19,20\}$. Quantities must be for an integer number of widgets and the aggregate quantity demanded by a bidder is restricted to be either in the interval $[0, Q]$ or $[0, Q / 2] .{ }^{8}$ Each quantity order is an offer to purchase the specified number of units at a price equal to (equal to or below in the case of the uniform-price auction) the price at which the order is submitted.

Beginning with quantities submitted at a price of $20 \mathrm{Fr}$, the "seller" aggregates all demands to create a downward sloping aggregate demand curve. The stop-out price is established as the highest price at which supply equals or exceeds the supply. Winning bids are those submitted at or above the stop-out price. All quantities demanded at prices strictly above the stop-out price are filled. Orders submitted at the realized stop-out price may be rationed.

Rationing is done in a pro-rata fashion. Specifically, the aggregate quantity demanded at the stop-out price is computed. For each bidder, the quantity demanded at the stop-out price is divided by the aggregate quantity demanded at the stopout price to determine the proportion of the rationed quantity that bidder is to receive. The rationed quantity is determined by subtracting the aggregate quantity demanded at all prices strictly above the stop-out price from the supply.

Given these characteristics we can describe Nash equilibria of the one-shot auction games for the symmetric capacity case in which all bidders may bid for the entire supply and for the asymmetric capacity case in which 2 of the five bidders are restricted from bidding for the entire supply and may only place bids for quantities up to $Q / 2$. In both cases, the uniform-price mechanism supports multiple equilibria. However, the only coalition proof equilibria are those for which the stop-out price is 17 (Proposition 1) so our analysis will concentrate on these equilibria. In the asymmetric capacity case, there are corresponding equilibria that are symmetric in the sense that all bidders with the same capacity (of the same type) play identical strategies (Proposition 2) and the strategies are identical across types except for marginal impacts dictated by the capacity constraints. The discriminatory auction has a single equilibrium in undominated strategies in both the symmetric and the asymmetric cases. In this equilibrium, the stop-out price is 19 and all bidders submit demands for their maximum allowable quantity at this price (Propositions 3 and 4).

PROPOSITION 1 [Symmetric Capacities]. There exist symmetric Nash equilibria of the uniform-price auction that result in stop-out prices at any of the four possible price levels. The only coalition proof equilibria result in a stop-out price of 17 , revenue for the seller of 442 , and profit per bidder per auction of 15.6.

\footnotetext{
8 We examine two different treatments (see below). In the "symmetric" case all bidders are allowed to bid for up to the entire quantity $Q$. In the "asymmetric" case 3 of the 5 bidders may bid for the entire quantity while 2 of the bidders may only bid for up to half the available supply. The inclusion of this asymmetry in the bidding capacity is the only difference between the current experimental design and implementation and that in SSZ (2006).
} 
PROPOSITION 2. [Asymmetric Capacities]. There exist Nash equilibria of the uniform-price auction that result in stop-out prices at each of the four possible price levels. The only coalition proof equilibria result in a stop-out price of 17, revenue for the seller of 442 , and profit for each large bidder of 15.8 per auction, and each small bidder of 15.3 per auction.

The proofs of Propositions 1 and 2 follow the development in Back and Zender (1993). A stop-out price below the known value of the good can be sustained in equilibrium by the use of steeply sloping bid functions. In a uniform-price format if the bid functions submitted by all bidders are sufficiently steep (inelastic), deviation by any bidder becomes unprofitable. Effectively, the marginal cost of capturing an additional unit is driven above the bid price by the steep bid functions of the other bidders in the uniform- price format as capturing an additional unit raises the price paid not only on that unit but on all units won by the bidder.

PROPOSITION 3 [Symmetric Capacities]. The only Nash equilibrium in undominated strategies in a discriminatory auction has all bidders submitting demands for 26 units at a price of 19. This implies seller's revenue of 494 per auction, and each bidder's profit is 5.2 per auction.

PROPOSITION 4 [Asymmetric Capacities]. The only Nash equilibrium in undominated strategies in a discriminatory auction has all bidders submitting the maximum allowable demands (either 26 or 13 units) at a price of 19. This implies seller's revenue of 494 per auction, and profit for each large bidder is 6.5 per auction while profit for each small bidder is 3.25 per auction.

The proofs of Propositions 3 and 4 follow due to standard competitive forces. If the stop-out price were at any level other than 19 or 20 there would be profitable deviations available to any bidder, regardless of the shape of the bid functions submitted by the other bidders. A stop-out price of 19 is an equilibrium outcome since any deviation resulting in greater quantity requires a bid at a price of 20 ; such a bid entails zero profit and is a weakly dominated strategy. The strategies useful in the uniform-price auction are not valuable because in a discriminatory format the marginal cost of winning an additional unit is always the price bid on that unit.

The theoretical results concerning equilibrium prices are exactly the same in the symmetric and asymmetric cases. However, the equilibrium allocations are different. In the symmetric case the allocations in the equilibria examined were, of course, all symmetric. Each bidder receives an allocation of 5.2 units in each auction. Given the asymmetry in the capacity constraint one expects to find that the players who have the ability to bid for more will receive a higher number of units. In the uniform-price auction the impact of the quantity restriction on the coalition proof Nash equilibria is marginal. The bidders who are allowed to submit bids for 26 units each have an equilibrium allocation of 5.266 units while those 
who are restricted to a total demand of 13 units have an equilibrium allocation of 5.101 units. This occurs because only one unit of the good is rationed amongst the 5 bidders in equilibrium despite the asymmetry in demands. In the discriminatory auction in the asymmetric case, because all the participants submit their entire allowable demand at the price of 19, the entire supply of 26 units is rationed. Bidders who may submit demands for 26 units will, therefore, get twice the allocation of those restricted to 13 units (6.5 and 3.25 respectively).

Within the current experimental design there are different ways the bidders may collude. The most beneficial is for each bidder to submit a single bid for a quantity that is no more than their assigned capacity at a price of 17 . If each bidder plays this strategy it will result in the lowest possible level of revenue for the seller and the highest possible level of aggregate profits for the bidders. This set of strategies is, however, not a Nash Equilibrium and requires collusive agreements among the bidder as there exist deviations that will provide large, one-time, profits for any individual bidder. As this is the "best collusive" arrangement the bidders may engage in we label it perfect collusion. ${ }^{9}$ In the sequel, we call any individual auction in which the bidders coordinate on this strategy a perfectly collusive auction and any experimental session in which all of the auctions are perfectly collusive a perfectly collusive session.

The equilibrium results described above ignore the possibility of collusion on the part of the bidders. While a large body of experimental evidence indicates that 4 players are sufficient in many situations to imply a competitive outcome (5 are used in the current experiment) Sherstyuk (1999) shows that pure common value auctions often result in collusion and Kwasnica (2000) demonstrates that communication between players increases this tendency. This evidence suggests that, in the current experimental setting, some amount of collusive behavior is to be expected on the part of the bidders. Furthermore there exist relatively large incentives for collusion in the current design. With the final value of the good common knowledge, competitive behavior would result in zero profits (equilibrium in the uniform-price auctions). In the Nash equilibrium for the discriminatory auction profits per bidder in the symmetric case are $5.2 \mathrm{Fr}$ per auction or a minimum of $72.8 \mathrm{Fr}$ ( $\$ 7.28$ with the conversion rate of $1 \mathrm{Fr}=\$ 0.10$ ) over the (minimum of $) 14$ rounds of bidding in a session. By colluding on a price of 17Fr bidders can achieve an average profit of $15.6 \mathrm{Fr}$ per auction or a minimum of $218.4 \mathrm{Fr}(\$ 21.84)$ over 14 rounds of bidding. SSZ (2006) found both collusive and competitive behavior in this same setting, with the discriminatory auctions being more susceptible to collusion.

\footnotetext{
9 While there exist many other sets of strategies that require collusive agreements among the bidders to maintain (for example the bidders could all agree to submit bids only at a price of 18) we focus on this particular set. Its ease of identification, the fact that it provides the largest profits, and requires the same level of trust as any other set of non-Nash strategies to maintain makes it a natural focal point when studying collusive behavior.
} 
Considering the possibility of collusion and given the finding in SSZ (2006) that the discriminatory auction was more susceptible to collusion, if the asymmetry in capacity constraints is effective in limiting collusion we expect:

1. Perfect collusion is predicted to be less likely in the asymmetric capacity treatments than it is in the symmetric capacity treatments.

2. Asymmetric bidding capacities are expected to have a larger impact (by limiting collusion) in the discriminatory auctions than in the uniform-price auctions.

In the absence of collusion, the theoretical predictions from the Nash equilibria of the one-shot game provide the following hypotheses:

3. Average revenue is expected to be higher under the discriminatory mechanism than it is for the uniform-price auction for both the symmetric and the asymmetric cases.

4. The average revenue (for both the uniform-price and discriminatory auctions) in the asymmetric capacity constraint treatment is expected to be the same as that obtained in the symmetric capacity treatment.

\section{Experimental Design}

\subsection{AUCTION RULES}

The auctions rules employed here are identical to those used in SSZ (2006) with one major difference - the introduction of asymmetry in bidding capacities. The same software, instructions, procedures, and rewards were employed as in that earlier study. More specifically, in the current setting, in each auction subjects bid for units of a good that we call widgets. As discussed above, there were 26 widgets available for sale in each auction. All monetary values are denominated in an experimental currency referred to as Francs (Fr). The resale value of each widget auctioned was 20Fr for all subjects, and this was common knowledge. Subjects submitted bid schedules at computer terminals. In the symmetric treatments all bidders could submit demands for the entire supply. In the asymmetric treatments, three of the subjects were permitted to bid for at most 26 units in total (the total supply) at the permissible prices $17 \mathrm{Fr}, 18 \mathrm{Fr}, 19 \mathrm{Fr}$, and $20 \mathrm{Fr}$ while two of the subjects were permitted to bid for at most 13 units. Although it was common knowledge that bidding capacity was asymmetric across the players, the exact distribution of bidding capacity was not necessarily common knowledge, each participant had the right but not the obligation to truthfully reveal his/her bidding capacity constraint.

Once all the bid schedules are submitted, the computer assigns widgets to subjects, allocating supply to the highest bids. When necessary demand at the stop-out price was rationed on a pro-rata basis as discussed above. In the uniform-price auctions, all the subjects pay the same price (the stop-out price) for each widget 
allocated and their payoff from each auction equals the difference between the resale value for each widget $(20 \mathrm{Fr})$ and the stop-out price times the number of widgets allocated. Under the discriminatory auction, the computation of each subject's payoff is similar except that each unit allocated is purchased at the bid price for each unit won.

\subsection{EXPERIMENTAL METHODOLOGY}

Each experimental session consisted of 5 subjects and each cohort of 5 subjects was involved in a single experimental treatment. We employed both students from Israel and from the US in this study. ${ }^{10}$ The students were undergraduate, MBA, MA and MIS students. All had had at least one course in finance, and courses in statistics and economics.

Table I lists the information pertaining to each experimental session. Thirteen repetitions of the uniform-price (four in Israel, four in Florida and five in Arizona) and thirteen repetitions of the discriminatory (four in Israel, four in Florida, and five in Arizona) treatments were conducted for the symmetric case. ${ }^{11}$ Eight repetitions of the uniform-price (four in Israel and four in Florida) and eight repetitions (four in Israel and four in Florida) of the discriminatory treatments were conducted for the asymmetric case. There were at least 14 auctions conducted in each experimental session, where the exact number was randomly chosen. In order to control for experience effects, we analyze only the first 14 auctions in each session.

At the start of each experimental session, subjects were seated in a conference room and given written instructions (in English in the U.S and in Hebrew in Israel). The instructions explained the auction rules, limits and timing of communication, the basis on which cash payments would be made, and included images that introduced the subjects to the software used to conduct the experiment. The instructions were read aloud, and subjects were then given the opportunity to ask clarifying questions. The student subjects were then given a quiz to ensure their understanding of the bidding and allocation rules. (A copy of the written instructions in English, sample computer screens and the quiz are included in the appendix that can be viewed at http://www.univie.ac.at/rof/papers/supplements/SadeSchnitzlein-Zender_Divisible Good Auctions_supplement.pdf.)

10 The sessions in the US were conducted at the University of Central Florida and the University of Arizona. The sessions in Israel were conducted at the Hebrew University of Jerusalem. The use of different locations serves as a robustness test to check that cultural differences are not driving our results.

11 The results of the sessions in Arizona are also documented in SSZ (2006). These sessions were conducted under identical conditions to those conducted in Israel and Florida. Given the benefit of an increased number of sessions to investigate and the fact that there is no significant difference in the behavior between the subjects in Florida or Israel and Arizona we include them in our sample. We note any qualitative differences in the results that occur from the exclusion of the Arizona data from the sample. 
Table I. Experimental sessions and summary statistics of the asymmetric setting

The table lists the experimental sessions conducted according to the date, mechanism, and the location and reports average prices and revenues. Bidding is permitted at four prices $(20,19,18$, 17) and it is common knowledge that the resale value at the end of each auction is 20. In sessions with asymmetric bidding capacities, three bidders may bid for up to 26 units while the remaining bidders are restricted to 13 units. When bidding capacities are symmetric, all five bidders may bid for up to 26 units.

\begin{tabular}{|c|c|c|c|c|}
\hline \multicolumn{5}{|c|}{ Panel A. Uniform-Price Mechanism } \\
\hline Date & Mechanism, bidding capacities, and location & $\begin{array}{l}\text { Mean stop-out } \\
\text { price }\end{array}$ & $\begin{array}{c}\text { Mean price } \\
\text { per unit }\end{array}$ & $\begin{array}{l}\text { Mean } \\
\text { revenue }\end{array}$ \\
\hline & Uniform-Price Symmetric Bidding Capacities & & & \\
\hline $10 / 7 / 2004$ & Hebrew University (Israel) & 17.0 & 17.0 & 442 \\
\hline $10 / 17 / 2004$ & Hebrew University (Israel) & 17.5 & 17.5 & 455 \\
\hline $11 / 6 / 2004$ & Hebrew University (Israel) & 18.2 & 18.2 & 474 \\
\hline $11 / 15 / 2004$ & Hebrew University (Israel) & 19.0 & 19.0 & 494 \\
\hline $9 / 16 / 2004$ & University of Central Florida (USA) & 18.3 & 18.3 & 475 \\
\hline $9 / 23 / 2004$ & University of Central Florida (USA) & 19.5 & 19.5 & 507 \\
\hline $9 / 30 / 2004$ & University of Central Florida (USA) & 17.0 & 17.0 & 442 \\
\hline $11 / 3 / 2004$ & University of Central Florida (USA) & 18.9 & 18.9 & 490 \\
\hline $02 / 26 / 2002$ & University of Arizona (USA) & 17.5 & 17.5 & 455 \\
\hline 04/10/2002 & University of Arizona (USA) & 18.5 & 18.5 & 481 \\
\hline 04/03/2002 & University of Arizona (USA) & 17.0 & 17.0 & 442 \\
\hline $10 / 21 / 2002$ & University of Arizona (USA) & 18.9 & 18.9 & 490 \\
\hline \multirow[t]{3}{*}{$10 / 24 / 2002$} & University of Arizona (USA) & 17.0 & 17.0 & 442 \\
\hline & Mechanism Averages & 18.0 & 18.0 & 468.4 \\
\hline & Uniform-price Asymmetric Bidding Capacities & & & \\
\hline $11 / 19 / 2003$ & Hebrew University (Israel) & 17.0 & 17.0 & 442 \\
\hline $4 / 5 / 2004$ & Hebrew University (Israel) & 17.7 & 17.7 & 461 \\
\hline $1 / 4 / 2005$ & Hebrew University (Israel) & 19.5 & 19.5 & 507 \\
\hline $12 / 28 / 2004$ & Hebrew University (Israel) & 18.1 & 18.1 & 472 \\
\hline $2 / 18 / 2004$ & University of Central Florida (USA) & 19.3 & 19.3 & 501 \\
\hline $2 / 23 / 2004$ & University of Central Florida (USA) & 17.9 & 17.9 & 466 \\
\hline $3 / 3 / 2004$ & University of Central Florida (USA) & 18.1 & 18.1 & 470 \\
\hline \multirow[t]{2}{*}{$1 / 13 / 2005$} & University of Central Florida (USA) & 18.1 & 18.1 & 470 \\
\hline & Mechanism Averages & 18.2 & 18.2 & 473.6 \\
\hline
\end{tabular}

Communication was explicitly allowed during the experiment. ${ }^{12}$ Prior to the start of each auction round there was a short period expressly identified as a period for discussion between subjects, nevertheless, subjects were allowed to discuss strategies and outcomes with each other at any time (before, during, and after each auction). ${ }^{13}$ The layout of the computer lab, however, prevented each subject

\footnotetext{
12 Isaac and Walker (1985) and Kwasnica (2000) discuss the relation between communication and collusion.

13 Communications were continually monitored by the facilitator to ensure they remained within the specified limits.
} 
Table I. Experimental sessions and summary statistics of the asymmetric setting (continued)

\begin{tabular}{|c|c|c|c|c|}
\hline \multicolumn{5}{|c|}{ Panel B. Discriminatory Price Mechanism } \\
\hline Date & Mechanism, bidding capacities, and location & $\begin{array}{l}\text { Mean stop-out } \\
\text { price }\end{array}$ & $\begin{array}{c}\text { Mean price } \\
\text { per unit }\end{array}$ & $\begin{array}{c}\text { Mean } \\
\text { revenue }\end{array}$ \\
\hline & Discriminatory-Price Symmetric Bidding Capacities & & & \\
\hline $10 / 1 / 2004$ & Hebrew University (Israel) & 17.7 & 17.7 & 461 \\
\hline $10 / 10 / 04$ & Hebrew University (Israel) & 17.0 & 17.0 & 442 \\
\hline $10 / 24 / 04$ & Hebrew University (Israel) & 19.0 & 19.0 & 494 \\
\hline $11 / 29 / 04$ & Hebrew University (Israel) & 17.0 & 17.0 & 442 \\
\hline $9 / 15 / 2004$ & University of Central Florida (USA) & 18.8 & 18.8 & 490 \\
\hline $9 / 22 / 2004$ & University of Central Florida (USA) & 17.9 & 18.1 & 471 \\
\hline $9 / 29 / 2004$ & University of Central Florida (USA) & 17.0 & 17.0 & 442 \\
\hline $10 / 13 / 2004$ & University of Central Florida (USA) & 18.7 & 18.9 & 491 \\
\hline $04 / 26 / 2002$ & University of Arizona (USA) & 17.0 & 17.0 & 442 \\
\hline 06/10/2002 & University of Arizona (USA) & 17.7 & 18.1 & 469 \\
\hline 07/17/2002 & University of Arizona (USA) & 17.1 & 17.9 & 465 \\
\hline $10 / 23 / 2002$ & University of Arizona (USA) & 18.6 & 18.8 & 489 \\
\hline \multirow[t]{3}{*}{$10 / 25 / 2002$} & University of Arizona (USA) & 17.0 & 17.0 & 442 \\
\hline & Mechanism Averages & 17.7 & 17.9 & 464.7 \\
\hline & Discriminatory-Price Asymmetric Bidding Capacities & & & \\
\hline $11 / 19 / 2003$ & Hebrew University (Israel) & 17.0 & 17.1 & 444 \\
\hline $12 / 12 / 2003$ & Hebrew University (Israel) & 18.7 & 18.9 & 492 \\
\hline $12 / 14 / 2003$ & Hebrew University (Israel) & 17.9 & 18.3 & 475 \\
\hline $12 / 14 / 2003$ & Hebrew University (Israel) & 18.9 & 19.2 & 499 \\
\hline $2 / 11 / 2004$ & University of Central Florida (USA) & 17.5 & 17.6 & 458 \\
\hline $2 / 16 / 2004$ & University of Central Florida (USA) & 18.9 & 19.0 & 494 \\
\hline $3 / 4 / 2004$ & University of Central Florida (USA) & 18.4 & 18.6 & 484 \\
\hline \multirow[t]{2}{*}{$11 / 4 / 2004$} & University of Central Florida (USA) & 17.0 & 17.0 & 442 \\
\hline & Mechanism Averages & 18.0 & 18.2 & 473.5 \\
\hline
\end{tabular}

from seeing the screen of any other subject, and subjects were informed that this would be counter to the auction rules. Therefore, while communication was open, actual bidding behavior remained private knowledge. After the final auction in each session each subject's screen automatically reverted to a blank screen (to maintain the privacy of bidding behavior as subjects left the lab) and subjects were paid individually in a side room. The "exchange" rate was fixed at $1 \mathrm{Fr}=\$ 0.10$ and payments averaged $\$ 20$ per subject.

The auctions were conducted with custom designed software. In addition to allowing the entry of bids, the software graphed individual demand curves in real time as each subject initiated the bid submission process. The aggregate demand schedule, stop-out price, and allocations for each round were calculated by the software at the completion of each auction. After each round each bidder was provided with information on the number of total units demanded at each price. In addition, the interface provided each bidder with historical information pertaining to their previously submitted demand functions matched with their allocations, profit, and 
percentage of available supply received for all of the completed auctions. Each experimental session lasted approximately one hour.

\section{Experimental Results}

The focus of this study is on how asymmetric bidding capacities affect the competitive dynamic and the relative performance of the uniform-price and the discriminatory mechanisms. In SSZ (2006), two versions of a uniform-price auction mechanism were found to be less susceptible to collusion than the discriminatory mechanism and so we expect the impact of the capacity constraints to be different across the different mechanisms. Before taking up these issues we first consider some basic characteristics of the bidding behavior.

\subsection{BIDDING BASICS}

Propositions 3 and 4 indicate that bidding in a discriminatory auction at a price of $20 \mathrm{Fr}$ is a weakly dominated strategy in a one-shot game. In the symmetric treatments, this dominated strategy was rarely played: in only 8 of the $182(4.4 \%)$ discriminatory auctions did any bidder submit orders at a price of $20 \mathrm{Fr}$. It is also true that all such bids came from only four bidders. Thus only 4 of the $65(6.2 \%)$ bidders that participated in the discriminatory auctions submitted a bid that was weakly dominated in this way.

Asymmetric bidding capacities increase the propensity for bidders to submit orders at a price of $20 \mathrm{Fr}$. In 5 of the 8 discriminatory sessions there were multiple auctions in which at least one bidder employed this strategy. Over all the asymmetric discriminatory sessions, at least one bidder had 20Fr as part of his/her bid curve in 25 of the $112(22.3 \%)$ auctions. This ratio is significantly higher than in the symmetric bidding capacities setting $(p<0.01) .{ }^{14}$ In total, 11 of the $40(27.5 \%)$ bidders employed this strategy at least once. If we examine this question at the session level (in order to make the most conservative correction for the possible lack of independence between auctions with in a session) we see that on average in the symmetric treatments 0.2 bidders per session bid at $20 \mathrm{Fr}$ in the discriminatory auction. In the asymmetric treatments an average of 1.1 bidders per session submitted bids at 20Fr. This difference is significant at the $10 \%$ level $(p=0.09)$ in a two-tailed $t$-test.

Although bids at 20 are weakly dominated in the one-shot game they can be part of a retaliation/punishment strategy in our multiple auction setting. Determining the motive for such a bid is difficult; however evidence on whether they rare due to "mistakes" can be gained by examining when they occurred in the session. Bids at $20 \mathrm{Fr}$ in the first auction would seem most likely due to a misunderstanding of the auction rules, rather than due to a retaliation or punishment strategy, since no auction information is received until all bidders have submitted their demands.

\footnotetext{
14 All comparisons across samples use Fisher exact tests unless otherwise noted.
} 
After the first auction, bidders receive clear feedback that would indicate that bids at $20 \mathrm{Fr}$ are never profitable. In fact, there were only 2 bids at $20 \mathrm{Fr}$ (for a single unit) in the first auction of any of the 8 sessions. Weighting the timing of such bids by the quantity demanded at $20 \mathrm{Fr}$ the average occurrence of bids at $20 \mathrm{Fr}$ was between the 10th and 11th auction in each session. Furthermore, in no case did such a bid occur after the bidders had successfully colluded. This evidence is consistent with these bids being part of a strategy to induce cooperation in future auctions. The increased use of this type of bid in the asymmetric treatments is consistent with there being a more difficult coordination problem in these auctions.

If the occurrence of bids at $20 \mathrm{Fr}$ is an indication of punishment strategies being played it is interesting to see if the use of such strategies differs as a function of the capacity constraint. It is not clear, ex ante, what to expect from this analysis. While the constrained bidders may have a heightened interest in establishing collusion, all bidders benefit from the perfectly collusive arrangement. More of the capacity constrained bidders, 6 of $16(37.5 \%)$, submit bids at 20Fr in the asymmetric discriminatory auctions than did the unconstrained bidders, 5 of $24(20.8 \%)$, in these auctions. This difference, however, is not statistically significant $(p=0.30)$. Accounting for volume by comparing the proportion of total potential volume bid at $20 \mathrm{Fr}$ across the two groups we see that $3.3 \%$ of total demand is submitted at a price of $20 \mathrm{Fr}$ by capacity constrained bidders while only $1.6 \%$ of total demand is submitted at a price of $20 \mathrm{Fr}$ by unconstrained bidders. This difference is also insignificant $(p=0.40)$ at the session level. Overall the evidence suggests that both types of bidders pursue punishment strategies with equal zeal. ${ }^{15}$

Bidding for fewer units than a bidder's capacity in an auction is also a weakly dominated strategy. In the symmetric treatments this strategy was employed in only 23 of the $364(6.3 \%)$ auctions and, on average, bidders bid for $99.8 \%$ of their capacity. In sharp contrast, bidding below capacity is much more frequent when bidders have asymmetric capacities, occurring in 10 of 16 sessions and 79 of 224 auctions (35.3\%). In 66 of these 79 auctions at least two bidders followed this strategy. These differences are significant using each session as an independent observation. In the discriminatory auctions with asymmetric capacity constraints, on average, more than half (2.875) of the players in each session did not bid for the maximum amount. In the symmetric discriminatory auctions on average less than one bidder did so. This difference is significant ( $p=0.02, t$-test). In the asymmetric uniform-price auctions, on average a little fewer than half (2.1) of the bidders bid for less than their capacities while in the symmetric uniform-price auctions the average was again less than one. This difference is marginally significant ( $p=$ $0.10, t$-test). Thus, we find that voluntarily bidding for less than a bidder's capacity is indeed more frequent when bidders have asymmetric capacities. This behavior is likely to play a role in the development of collusive strategies.

Bidder behavior also differed based upon the level of the constraint. In the discriminatory auctions, bidders with a capacity constraint of 13 on average bid

15 See also Kwasnica and Sherstyuk (2005). 
$88.4 \%$ of their capacity, while unconstrained bidders on average bid for $76.4 \%$ of capacity. In the uniform-price auctions a similar result obtains with average bids of $92.6 \%$ and $85.1 \%$ of their capacities respectively. Weighting each auction equally $(n=112)$, both differences are highly significant $(p<0.01)$. However, treating each session as an independent observation the difference is significant for the discriminatory auctions ( $p=0.10, t$-test) but not for the uniform-price auctions ( $p=0.28, t$-test). This finding is consistent with the prediction that the effect of asymmetric capacities will have more of an impact in the discriminatory auctions. Further, if voluntarily "removing" the asymmetry (bidding below capacity by the unconstrained bidders) is an important component of sustainable collusion this result is also consistent with the finding that the discriminatory auctions are more susceptible to collusion (SSZ (2006)).

In sum, the evidence indicates that bidders behave differently in the symmetric and asymmetric capacity environments. Further, in the asymmetric setting bidders behave differently as a function of their capacity constraints. We now turn to an examination of collusion.

\subsection{COLLUSION}

Our experimental setting is such that there are sufficient competitors to expect a competitive outcome, although by permitting open communication, the barriers to cooperation and coordination are low. SSZ (2206) found substantial collusion, and found the discriminatory auctions to be more susceptible to collusion than were the uniform-price auctions. In this subsection we begin to examine the main concern of the paper, the interaction between asymmetry in bidding capacities and collusion.

We start by investigating how asymmetry in bidding capacities affects the likelihood an entire session will be collusive. SSZ (2006) defines a "perfectly collusive outcome" to be an auction outcome in which each bidder submits his/her entire demand of 26 units at the lowest permissible price (17) and a perfectly collusive session as one in which all auctions are perfectly collusive. This implies revenue to the auctioneer of 442Fr in each perfectly collusive auction. Under the uniformprice mechanism, perfect collusion is distinguished from the coalition-proof Nash equilibrium that implies the same revenue by the incentive each bidder has to defect (in a one-shot game) from the strategy. We use a similar definition, adjusting for the capacity constraints and possible implications of these constraints. In particular we define a collusive outcome to be an auction in which each bidder submits their total quantity demanded (as distinct from potential demand) at a price of 17.

In the symmetric treatments, 4 of the 13 (30.8\%) sessions conducted using a uniform-price format and 5 of $13(38.5 \%)$ sessions using the discriminatory format were perfectly collusive. In the asymmetric treatments, 1 of $8(12.5 \%)$ sessions were perfectly collusive in both the uniform-price and discriminatory auctions. In total, 9 of $26(34.6 \%)$ sessions are collusive when capacity constraints are sym- 
metric. ${ }^{16}$ With asymmetric capacity constraints, across both types of auctions, the number of collusive sessions falls to 2 of 16 (12.5\%).

We use two separate approaches to consider the statistical significance of these differences. First, within each auction category we test whether the event of observing collusion (c) is as likely as the event of observing no collusion (nc) across the different types of sessions. Specifically we take as the null hypothesis that $\operatorname{prob}[\mathrm{c}]=\operatorname{prob}[\mathrm{nc}]=0.5$ with the alternative hypothesis being $\operatorname{prob}[\mathrm{c}]<\operatorname{prob}[\mathrm{nc}]$. For both the discriminatory and the uniform-price auctions with asymmetric capacities, of the eight sessions only one is perfectly collusive. Using a binomial test, the probability of observing at most one such session under the null is 0.035 . The null can be rejected in favor of the alternative hypothesis that collusion is less likely than no collusion in the asymmetric treatments for both auction types. Applying the same test to the symmetric cases, yields insignificant p-values so the null hypothesis of equal probabilities of collusive and non-collusive behavior in the symmetric treatments cannot be rejected for either type of auction $(p=0.29$ for the discriminatory and $p=0.133$ in the uniform-price auctions). ${ }^{17}$

Secondly, we estimate a Probit model of the likelihood of perfect collusion controlling for the asymmetry of capacity constraints and the pricing rule used in the auction to directly evaluate whether the probability of a collusive session is less likely when there are asymmetric capacity constraints. Specifically, we estimate the following model:

$$
\mathrm{PC}=b_{1}+b_{2} \mathrm{UF}+b_{3} \mathrm{ASYMMETRY}+\varepsilon
$$

where PC is an indicator variable for whether a session is perfectly collusive, UF is an indicator for whether the session was made up of uniform-price auctions, and ASYMMETRY is an indicator for whether the session included asymmetric capacity constrained bidders. The sample includes all 42 sessions. The coefficient estimates and corresponding $z$-statistics are:

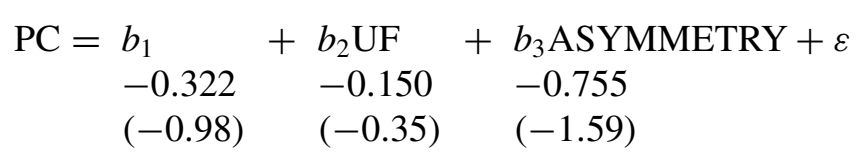

The $R$-square of the regression is 0.064 and $74 \%$ of the predictions are correct. The negative coefficient indicates, consistent with prediction 1 , that asymmetric capacity constraints make it significantly $(p=0.06 \text {, one-tailed test })^{18}$ less likely that any session is perfectly collusive. ${ }^{19}$ Both tests indicate that, consistent with

\footnotetext{
16 Excluding the sessions from Arizona, $31.3 \%$ of the sessions are collusive.

17 The conclusions of this test do not differ if we exclude the sessions run in Arizona.

18 If we exclude the Arizona sessions the coefficient on ASYMMETRY remains negative and significant $(p=0.10)$.

19 By including an interaction of UF and ASYMMETRY we can also directly test prediction 2 (that asymmetric bidding capacities will have a larger impact in the discriminatory auctions than in
} 
prediction 1, asymmetry in bidding capacities plays a significant role in inhibiting collusion.

Rather than require a session to begin and maintain perfect collusion, it is also interesting to consider the behavior of the bidders in the final auction of each session as an indication of the outcomes to which the bidders converge as they gain experience. ${ }^{20}$ In the symmetric capacity version of the discriminatory auction, the participants converged solely to the Nash equilibrium (4 of 13 or $30.8 \%$ of the sessions) or to the perfectly collusive outcome ( 9 of 13 or $69.2 \%$ of the sessions, see Table II panels $\mathrm{C}$ and $\mathrm{D}$ ). With asymmetric bidding capacities in the discriminatory auction the participants converged to the perfectly collusive outcome less frequently (3 of 8 or $37.5 \%$ of the sessions) and converged to the Nash outcome in only a single session. In the uniform-price auctions, symmetric bidders converged to the collusive outcome in the final round in 6 of 13 (46.2\%) sessions. In the uniform-price auctions, asymmetric bidders converged to the collusive outcome in 2 of $8(25 \%)$ sessions. $^{21}$ There was no instance in which the bidders in a uniform-price auction converged to a Nash equilibrium outcome.

Examining the convergence of the outcomes, rather than the ability of the bidders to sustain the collusion for the entire session, we see that the symmetric treatments are more likely to result in collusive outcomes than are the asymmetric treatments. These differences are, however, not statistically significant. While it is nearly twice as likely for bidders in symmetric auctions converge to the collusive outcome as it is in the asymmetric auctions (for both auction types), for neither type of auction nor type of capacity constraint can we reject the null hypothesis that perfect collusion and non-collusion are equally likely in the final auction.

Consistent with an increased difficulty of sustaining collusion in the asymmetric sessions, the results described above also suggest that asymmetric capacities make the convergence to any particular outcome more difficult. We first examine differences in the sustainability of the collusive outcome in discriminatory auctions across the different capacity treatments. Conditional on realizing the perfectly collusive outcome in any auction the probability that the collusive outcome was realized in the subsequent auction of the same session was $95.4 \%$ when bidders had symmetric bidding capacities. When bidders had asymmetric capacity constraints this conditional probability was $87.5 \%$. This difference is significant at the $10 \%$ level. Similarly, conditional on observing the Nash equilibrium in any auction the probability of observing this outcome in the subsequent auction across the different capacity treatments is as follows. With asymmetric bidding capacities in discrim-

the uniform-price auctions). Estimating this model we see that the coefficient on ASYMMETRY remains significant at the $10 \%$ level and the coefficient on the interaction term is of the correct sign (positive) but is not statistically significant.

20 If we instead consider the final two or three auctions of each session the conclusions are the same (see Table II).

21 These patterns differ very little if we instead consider the last two or three rounds instead of only the last round. 
inatory auctions this probability is $45.4 \%$ while with symmetric bidding capacities it is a significantly higher $84 \%(p<0.01)$. Asymmetric bidding capacities made it less likely that either the collusive outcome or the Nash equilibrium was sustained in successive auctions relative to the symmetric treatments.

In the uniform-price auctions the subjects never played Nash equilibrium strategies. The conditional probabilities of sustaining the collusive outcome across different capacity constraints are as follows. In the uniform-price auctions with asymmetric capacities the probability that a collusive outcome followed a collusive outcome was $57 \%$. In the uniform-price auctions with symmetric capacity constraints this probability is insignificantly different at $83 \%(p=0.2)$. These findings are also consistent with the hypotheses that asymmetry between bidders affects bidding behavior and that the effect is larger in the discriminatory auctions.

\subsection{REVENUE}

In this section we analyze the influence of the auction mechanism and asymmetry in capacity constraints on the seller's revenue. Average stop-out prices and revenues by session are reported in Table I. With symmetric capacity constraints, average revenue is 464.7 under the discriminatory price mechanism and 468.4 under the uniform price mechanism. With asymmetric capacity constraints, average revenue is 473.5 under the discriminatory mechanism and 473.6 under the uniform-price mechanism.

Figure 1 shows patterns in revenue as the subjects gain experience in a session. In order to smooth variation in the series presented in Table II and to highlight the impact of experience Figure 1 presents a moving average of realized revenue across successive auctions. Specifically, for each time series, the first point represents the average for all 14 auctions under each mechanism, the second point is the average for auctions 2 through 14, the third is the average for auctions 3 through 14, and so on. It is interesting to note that with asymmetric bidding capacities, revenue increases on average toward the end of the session under both auction mechanisms, while the reverse effect obtains with symmetric bidding capacities. This effect occurs in each of the groups of sessions (UCF symmetric and asymmetric bidding capacities, Hebrew University symmetric and asymmetric bidding capacities, and University of Arizona symmetric bidding capacities) and is consistent with the impact of asymmetric bidding capacities on the convergence to the collusive outcome discussed above. Figure 1 is consistent with prediction 1 and also demonstrates that while experience does impact the outcomes of the auctions the differences in behavior introduced by asymmetric bidding capacities do not seem to be driven by experience effects. 


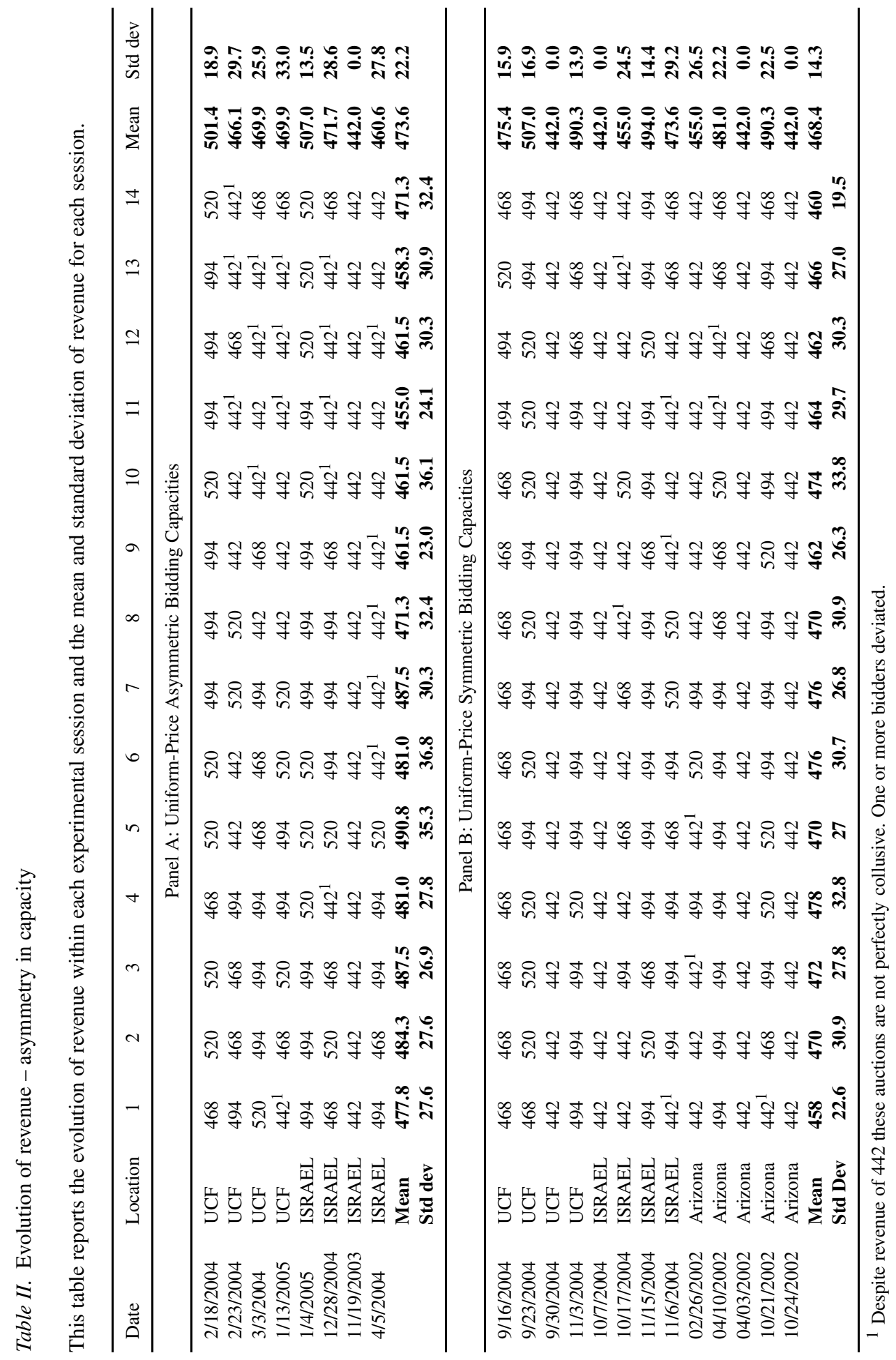




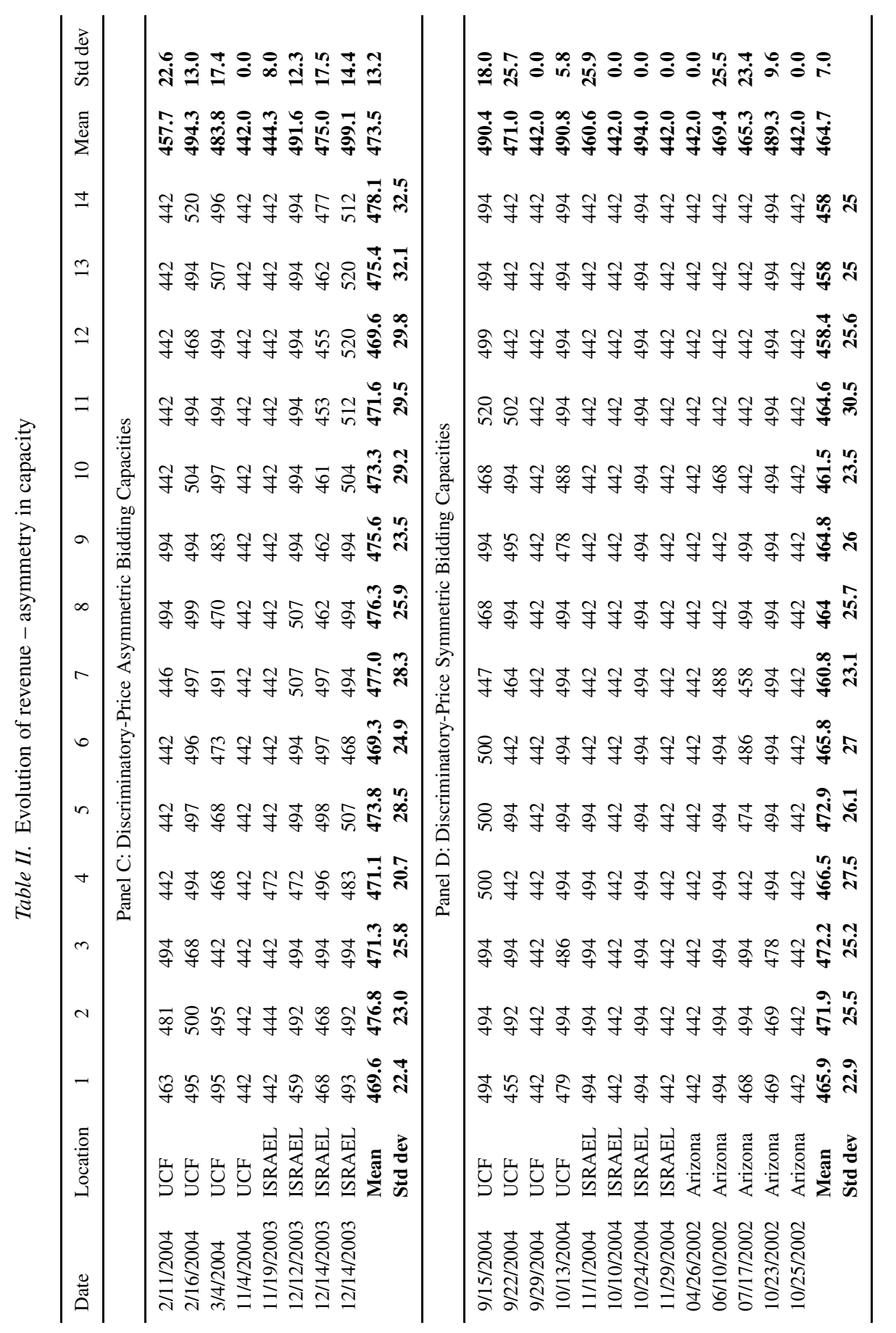



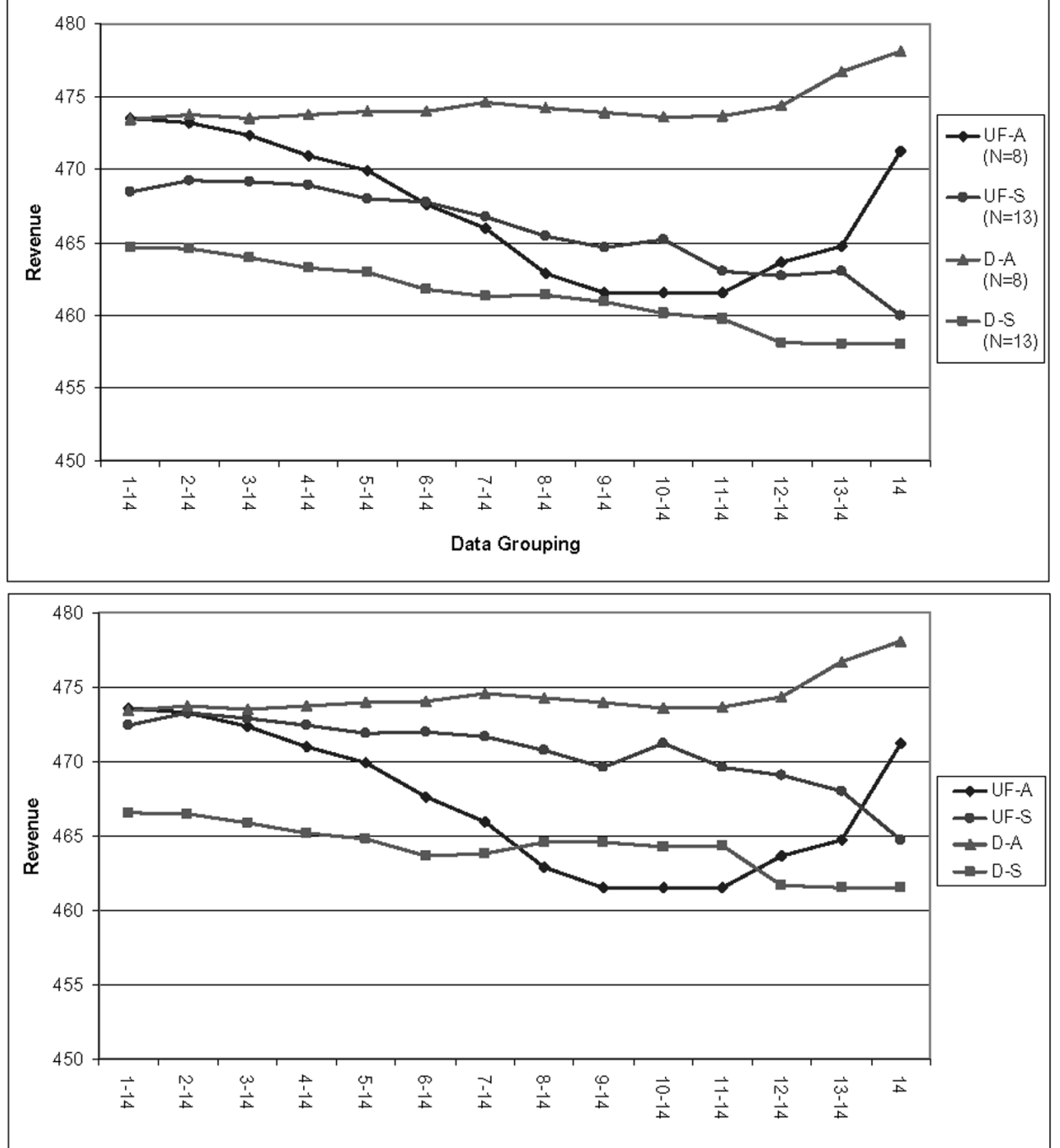

Figure 1. Experience effects. This figure shows the influence of experience on auctioneer's revenue by comparing results from later auctions with global averages. The first data grouping is the global average for all 14 auctions under each mechanism, the second data grouping is the average for auctions 2 through 14, the third is the average for auctions 3 through 14 and so on. The second figure excludes sessions with symmetric capacity constraints from SSZ (2006).

We next examine the relative importance of auction format compared with asymmetry in capacity constraints in determining revenue by estimating the following (Tobit) regression: ${ }^{22}$

$$
\text { REVENUE }=b_{1}+b_{2} \mathrm{UF}+b_{3} \text { ASYMMETRY }+\varepsilon
$$

22 In this experiment bidders cannot bid above $20 \mathrm{Fr}$ per unit or below $17 \mathrm{Fr}$ per unit so there is both a minimum and maximum revenue imposed by the experimental design. 
The variable definitions are as follows. REVENUE is revenue from the last auction in each session. ${ }^{23}$ UF is an indicator variable that takes on a value of 1 in uniform-price sessions and 0 otherwise. ASYMMETRY is an indicator variable that takes on the value of 1 in the sessions with asymmetric capacity constraints and zero otherwise. The indicator for the discriminatory mechanism is suppressed; the mean for the discriminatory sessions is captured by the intercept after controlling for ASYMMETRY, and the estimated coefficient for UF represents the difference between these session means and the mean for the discriminatory sessions. The sample consists of all 42 sessions.

The outcome of this regression is as follows:

$$
\begin{aligned}
& \text { REVENUE }=b_{1}+b_{2} \mathrm{UF}+b_{3} \text { ASYMMETRY }+\varepsilon \\
& 428.70 \quad 7.96 \quad 34.52 \\
& (25.31) \quad(0.44) \quad(1.83)
\end{aligned}
$$

The coefficient on the indicator for asymmetry in capacity constraints is positive and significant at the $10 \%$ level $(p=0.06)$. The revenue difference between the uniform-price and the discriminatory mechanism is not significant $(p=0.66)$. The $R^{2}$ of the regression is $7.06 \%$. These estimates indicate that asymmetry in bidding capacities increases expected revenue in both types of auctions while the differences in revenue across auction formats alone are not significant once the difference in capacity constraints is controlled for. These results, combined with the findings of section 4.2, suggest that asymmetric bidding capacities have an impact on revenue due to the role they play in facilitating competition (in both auction formats).

To more fully investigate the role of asymmetry in bidding capacities we perform an ANOVA $^{24}$ analysis for the differences in conditional average revenue (again measuring revenue as the revenue in the final auction of each session) controlling for the following conditions: auction type (discriminatory or uniformprice), capacity constraints (symmetric or asymmetric), and the nature of the outcome (perfectly collusive or not). The results are reported in panel A of Table III. In all collusive outcomes the revenue is, by definition, 442 so these cases are not separately discussed, we only note that each revenue level reported below

\footnotetext{
23 The last auction is used because experience has differential effects on competition as a function of capacity constraints. The last auction is most likely to be the closest to steady state outcomes. A similar outcome is obtained using the average of the last 2 or 3 auctions in each session. The coefficient estimates are similar however because when we average revenue across the auctions there is less cross sectional variation in revenue, the coefficient on the asymmetry variable is no longer statistically significant $(p=0.17)$.

24 The ANOVA is performed using an OLS regression of revenue on dummy variables for each of the conditions; essentially fixed effects for each of the eight categories of auction outcomes (e.g. symmetric, uniform, and collusive represents one category). Similar results are obtained if we use the average revenue for the final 2 or 3 auctions of each session rather than only the final round. Panel B of Table III presents the results using the final 3 rounds.
} 
Table III. ANOVA analysis

The ANOVA is performed using an OLS regression regressing the independent variable on dummy variables for each of the eight categories of auction outcomes: uniform-price symmetric non-collusive (USNC), uniform-price symmetric collusive (USC), discriminatory symmetric non-collusive (DSNC), discriminatory symmetric collusive (DSC), uniform-price asymmetric non-collusive (UANC), uniform-price asymmetric collusive (UAC), discriminatory asymmetric non-collusive (DANC), discriminatory asymmetric collusive (DAC). The coefficient estimates represent the average revenue in each category of auction outcome. The associated standard errors appear below each coefficient estimate. Panel A presents estimates based on the revenue of the 14th auction in each of the 42 sessions. Panel B presents the estimates using the average revenue for the 12th, 13th, and 14th auction of each session. Panel $\mathrm{C}$ presents estimates using the Hirfindahl-Hirschman index of allocations in the 14th auction in each session and Panel D uses the average Hirfindahl-Hirschman index of allocations across the 12th, 13th, and 14th auctions of each session.

\begin{tabular}{lcccccccc}
\hline Coefficient & USNC & USC & DSNC & DSC & UANC & UAC & DANC & DAC \\
\hline \multicolumn{7}{c}{ Panel A: Independent variable: Auction 14 Revenue } \\
\hline Coefficient estimate & 475.4 & 442.0 & 494.0 & 442.0 & 481.0 & 442.0 & 499.8 & 442.0 \\
Standard error & 5.49 & 5.92 & 7.26 & 4.84 & 5.92 & 10.26 & 6.49 & 8.38 \\
\hline & Panel B: Independent variable: Average Revenue Last 3 Auctions & & \\
\hline Coefficient estimate & 475.6 & 442.0 & 494.4 & 442.0 & 470.9 & 442.0 & 493.8 & 442.0 \\
Standard error & 6.07 & 7.67 & 8.58 & 5.72 & 7.01 & 12.13 & 7.67 & 9.91 \\
\hline \multicolumn{7}{c}{ Panel C: Independent variable: Auction 14 Hirfindahl-Hirschman Index } & \\
\hline Coefficient estimate & 5090.2 & 2000.0 & 2044.3 & 2000.0 & 3501.5 & 2104.8 & 4095.7 & 2076.3 \\
Standard error & 621.21 & 670.99 & 821.79 & 547.86 & 670.99 & 1162.18 & 735.03 & 948.92 \\
\hline \multicolumn{7}{c}{ Panel D: Independent variable: Average Hirfindahl-Hirschman Index Last 3 Auctions } \\
\hline Coefficient estimate & 4492.2 & 2000.0 & 2620.6 & 2000 & 3150.7 & 2124.2 & 3587.1 & 2007.7 \\
Standard error & 384.63 & 468.10 & 523.35 & 348.90 & 427.31 & 740.13 & 468.10 & 604.31 \\
\hline
\end{tabular}

for sessions that were not perfectly collusive is significantly different from 442 $(p<0.01$ in each case) .

For the discriminatory auctions with symmetric bidding capacities which were not collusive, average revenue was 494 . With asymmetric bidding capacities the discriminatory auctions that were not collusive the average revenue was 499.8. This difference is not significant $(p=0.49)$. Thus controlling for the absence of collusion there is not a significant difference in average revenue across the different capacity constraints in the discriminatory auction. This is consistent with prediction 4. For the uniform-price auctions with symmetric bidding capacities that were not collusive the average revenue was 475.4 . The uniform-price auctions with asymmetric bidding capacities that were not collusive had average revenue of 
481.0. As in the discriminatory auctions, this difference is also insignificant ( $p=$ 0.78). Controlling for the absence of collusion, asymmetric bidding capacities does not have a significant impact on revenue in the uniform-price auction. This is again consistent with prediction 4 . Consistent with prediction 1, in both the uniform-price and the discriminatory auctions the results of the regression in Equation (2) and the ANOVA analysis demonstrate that the effect of asymmetric capacity constraints on revenue derives from its role in limiting collusive behavior.

Finally, in the Nash equilibria examined in Section 2, the discriminatory auctions have higher equilibrium revenue than the coalition-proof equilibrium revenue in the uniform price auctions, with both types of capacity constraints (prediction 3). Conditional on a lack of collusion the actual bidding is consistent with this prediction. Specifically, the average revenue of 494 in the discriminatory auctions with symmetric capacity constraints is significantly higher than the average revenue of 475.4 in the uniform-price auctions with symmetric capacity constraints $(p=0.02)$. Similarly the average revenue of 499.8 for the discriminatory auctions with asymmetric bidding capacities is significantly higher than the average revenue of 481.0 for the uniform-price auctions with asymmetric bidding capacities ( $p=$ $0.07)$.

\subsection{ALLOCATIONS}

Table IV details the allocations in the asymmetric treatments according to capacity, mechanism type, and the location of the experiment. In our asymmetric treatments, three players had potential bidding capacities of 26 (unconstrained bidders) while two players had potential bidding capacities of 13 (capacity constrained bidders). The equilibrium of Proposition 4 for the discriminatory auction results in the following allocation: 6.5 units to the players that can submit 26 units and 3.25 units to the players that can submit 13 units. The actual allocation to high capacity bidders averaged 5.63 units. This is significantly less than the theoretical prediction ( $p=$ 0.06 ) and is consistent with the finding that high capacity bidders bid, on average, for only $76.4 \%$ of their capacity in these auctions. There are multiple equilibria in the uniform-price auction and therefore no clear prediction for comparison with actual allocations. In contrast to the discriminatory auctions, under the uniformprice mechanism unconstrained bidders averaged 6.2 units while the constrained bidders averaged only 3.7 units.

On average under both auction formats, the unconstrained bidders receive larger allocations. Unconstrained bidders received higher average allocations under the uniform-price mechanism than the discriminatory mechanism (6.20 versus 5.63, $p=0.14$ ). This implies that the allocation between the two types of bidders is more symmetric in the discriminatory price mechanism than in the uniform-price mechanism. ${ }^{25}$ We also find that under the discriminatory price mechanism the un-

\footnotetext{
25 A similar result is reported in SSZ (2006). This finding is consistent with the discriminatory auction being more susceptible to collusion than is the uniform-price auction.
} 


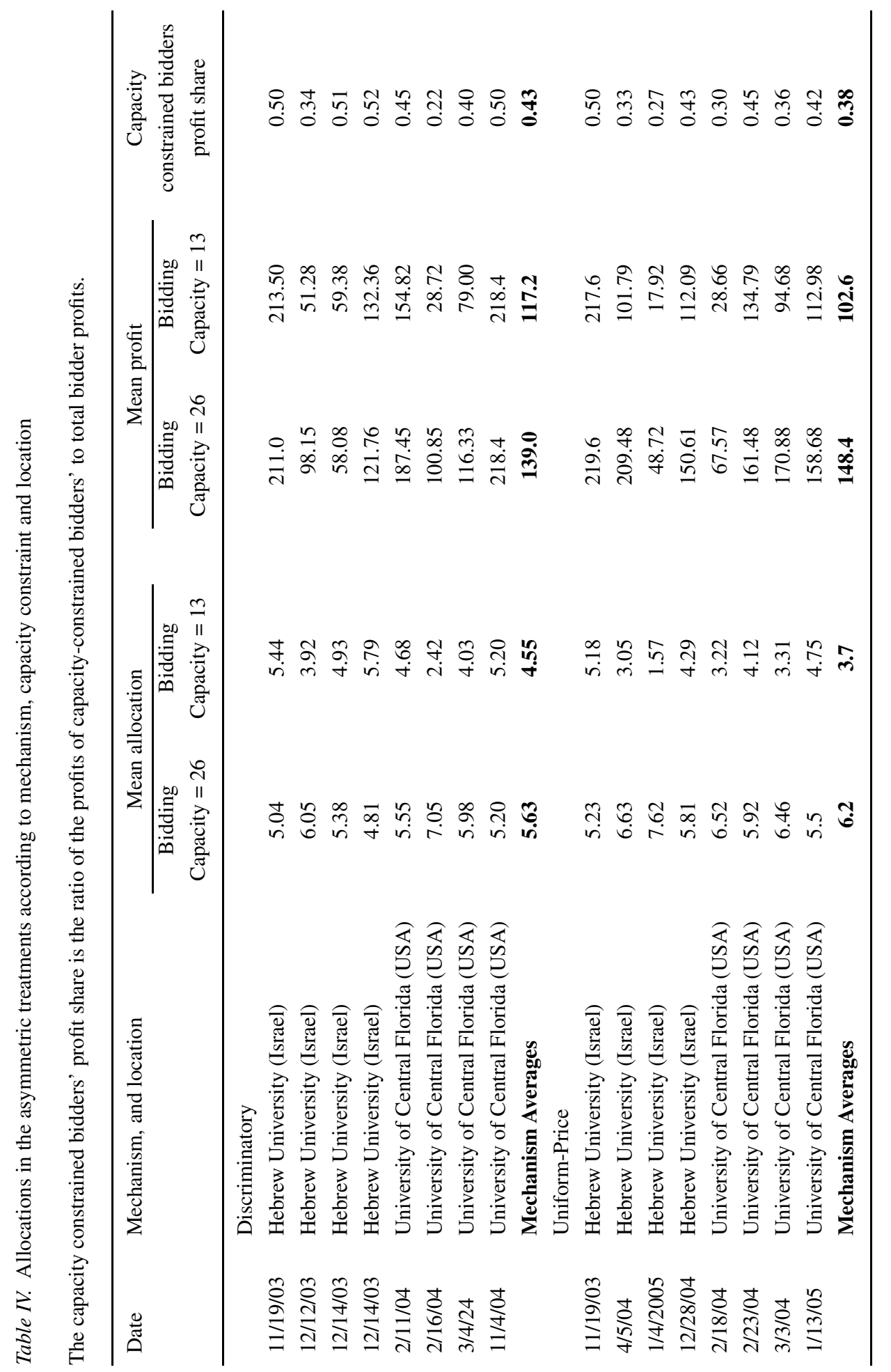


constrained bidders, on average, receive a lower allocation than the theory predicts while the capacity constrained bidders receive more on average. This reflects collusive agreements in which the bidders condition on their competitors' capacity constraints.

To further examine the symmetry of allocations of the good under the different mechanisms we compute the Herfindahl-Hirschman (HH) index (which is the sum of the squares of the percentage allocations across the bidders in a given auction) of the allocations. The range of values for this index with 5 bidders is $2000\left(5 \times 20 \%^{2}\right)$ if the allocation is perfectly symmetric to $10,000\left(100 \%^{2}\right)$ if a single bidder receives the entire allocation. We perform an ANOVA analysis measuring the conditional average values of the index in the last auction of each session controlling again for the presence or absence of collusion, whether the auction is uniform-price or discriminatory, and whether the outcome is collusive or not (see Panel C of Table III). Overall, the evidence is again consistent with the hypothesis that the impact of asymmetric capacity constraints is due to the limitations they place on collusive behavior.

In general, the average $\mathrm{HH}$ index is significantly higher in the non-collusive outcomes than in the collusive outcomes for all types of auctions. In the uniform-price auctions, with symmetric capacities the average $\mathrm{HH}$ index for the non-collusive auctions (5090) is significantly ( $p=0.01$ ) higher than the average for the collusive auctions (2000). In the uniform-price auctions with asymmetric capacities the average $\mathrm{HH}$ index for the non-collusive auctions (3501) is higher than the average for the collusive auctions (2104). This difference is not significant due to the small number of collusive outcomes in this type of auction. In the discriminatory auctions with asymmetric capacities the average $\mathrm{HH}$ index for the non-collusive auctions (4095) is significantly ( $p=0.05$ ) higher than the average for the collusive auctions (2076). In the discriminatory auctions with symmetric capacity constraints nearly all of the outcomes were either perfectly collusive or the Nash equilibrium outcome (described in Proposition 3), both of which imply perfectly symmetric allocations. The symmetry of allocations is therefore not significantly different in the collusive versus the non-collusive auctions in this case. These results suggest that symmetry of allocations is an important component of collusive behavior. ${ }^{26}$

Controlling for a lack of collusion, the average level of the HH index in the discriminatory asymmetric capacity auctions (4095) is significantly $(p=0.04)$ greater than the average (2044) for the discriminatory auctions with symmetric capacity constraints. On the other hand, again controlling for a lack of collusion, the average level of the $\mathrm{HH}$ index for the uniform-price auctions with asymmetric capacity constraints (3501) is insignificantly different from the average (5090) for the uniform-price auctions with symmetric capacity constraints. This is consistent with prediction 2 that the impact of asymmetry is greater in the discriminatory auctions than in the uniform-price auctions.

\footnotetext{
26 Performing the ANOVA analysis using an average of the HH index for the final 3 auctions provides similar results see Panel D of Table III.
} 


\subsection{BIDDING AGGRESSIVENESS AND PROFITS AS A FUNCTION OF CAPACITY CONSTRAINTS}

It is interesting to consider whether low capacity bidders bid more aggressively than high capacity bidders. In both types of auction, low capacity bidders bid more aggressively (submit bids with higher quantity-weighted average prices) than do high capacity bidders. The differences are, however, small and not statistically significant. We also measure aggressiveness with the first six units of each bidder's demand curve, since in many cases these will be most relevant in determining allocations and profits. The results are essentially unchanged.

On average, under both auction mechanisms, unconstrained bidders earned higher profits than capacity constrained bidders. Profits of capacity constrained bidders were $63.9 \%$ of those of unconstrained bidders under the uniform-price auction and $80.4 \%$ of the profits of unconstrained bidders under the discriminatory auction. Treating each session average as an observation, however, neither difference is significant due to the large variation across sessions.

\section{Conclusion}

We use an experimental approach to analyze the impact of asymmetry in capacity constraints on bidding in a divisible good auction. The experimental economics laboratory is a natural setting in which to study this issue due to the complicated nature of the auction game when the good is divisible and play is repeated. There is a clear and significant difference in the bidding behavior in the asymmetric versus symmetric setting which suggests that asymmetry plays an important role in determining bidder behavior and the competitive dynamic of the auctions. We show that asymmetry in capacity constraints plays an important role in inhibiting collusion and promoting competitive outcomes. This effect appears to be related to the increased difficulty of coordination when there are fundamental differences between bidders.

Asymmetry in capacity constraints plays a more important role in the discriminatory auction than in the uniform-price auction due to the greater susceptibility of the discriminatory auction to collusion. We show that asymmetry in capacity constraints increases the average revenue in both types of auctions and that this increase in revenue is derived from a reduction in collusive activity on the part of the bidders. We also find that while capacity constrained bidders may bid slightly more aggressively their constraint is effective in the sense that they receive, on average, a lower allocation and earn lower profits than their unconstrained counterparts.

The results regarding the level of collusion and the revenue obtained under each mechanism across different bidding capacity regimes suggest that the optimal auction format may depend heavily on factors specific to a particular setting. Universal and absolute revenue rankings may not exist in divisible good auctions.

While one is always cautious in drawing policy implications from an experiment in a stylized setting, we interpret our results as suggesting that existing auction 
policies which set demand limits, and so tend to make bidders similar with respect to bidding capacity, may be counter productive from this perspective. ${ }^{27}$ Instead, policies designed to attract more bidders to the auction may be more productive in encouraging competition and raising the seller's revenue.

\section{References}

Abbink, K., Brandts, J., and Pezanis-Christou, P. (2004) Auctions for government securities: A laboratory comparison of uniform, discriminatory and Spanish designs, unpublished working paper University of Nottingham.

Armantier, O. Sbaï, E. (2003) Estimation and comparison of treasury auction formats when bidders are asymmetric, forthcoming Journal of Applied Econometrics.

Ausubel, L. and Cramton, P. (2002) Demand reduction and inefficiency in multi-unit auctions, unpublished working paper University of Maryland.

Back, K. and Zender, J. F. (1993) Auctions of divisible goods: On the rationale for the treasury experiment, Review of Financial Studies 6, 733-764.

Back, K. and Zender, J. F. (2001) Auctions of divisible goods with endogenous supply, Economics Letters 73, 29-34

Bartolini, L. and Cottarelli, C. (1997) Designing effective auctions for treasury securities, Federal Reserve Bank of New York, Current Issues in Economics and Finance 9.

Benoit, J. P. and Krishna, V. (2001) Multiple-object auctions with budget constrained bidders, Review of Economic Studies 68(1), 155-179.

Crawford, V. P. (1997) Theory and experiment in the analysis of strategic interaction, in David Kreps and Den Wallis (eds.), Advances in Economics and Econometrics: Theory and Applications, Seventh World Congress, Vol. I, Econometric Society Monographs No. 27, Cambridge University Press, Cambridge, U.K., and New York, pp. 206-242.

Friedman, M. (1960) A Program for Monetary Stability, Fordham University Press, New York.

Garbade D. K. and Ingber, J. F. (2005) The treasury auction process: Objectives, structure, and recent adaptations, Federal Reserve Bank of New York, Current Issues in Economics and Finance, 11(2).

Goswami, G., Noe, T., and Rebello, M. (1996) Collusion in uniform-price auctions: Experimental evidence and implications for treasury auctions, Review of Financial Studies 9, 757-785.

Isaac, R. M. and Walker, J. M. (1985) Information and conspiracy in sealed bid auctions, Journal of Economic Behavior and Organization 6, 139-159.

Jegadeesh, N. (1993) Treasury auctions bids and the salomon squeeze, Journal of Finance 48, 14031420.

Kwasnica, A. M. (2000) The choice of cooperative strategies in sealed bid auctions, Journal of Economic Behavior and Organization 42, 323-346.

Kwasnica, A. M. and Sherstyuk, K. (2005) Collusion and equilibrium selection in auctions, unpublished working paper Penn State.

Klemperer, P. (2002) What really matters in auction design, Journal of Economic Perspectives 16(1), 169-189.

Kremer, I. and Nyborgm K. (2002) Divisible good auctions: The role of allocation rules, RAND Journal of Economics 35, 147-159.

Kremer, I. and Nyborg, K. (2003) Underpricing and market power in uniform price auctions, Review of Financial Studies 17, 849-877.

27 There are other reasons these limits exist. See the discussion in Jagedeesh (1993) of the Salomon squeeze in the U.S. Treasury auctions. 
Ledyard, O. J. (1995) Public goods: A survey of experimental research, in J. H. Kagel and R. E. Alvin (eds.), The Handbook of Experimental Economics, pp. 111-194.

LiCalzi, M. and Pavan, A. (2005) Tilting the supply schedule enhances competition in uniform-price auctions, European Economic Review 49, 227-250.

McAdams, D. (2005) Adjustable supply in uniform-price auctions: The value of non-commitment, unpublished working paper MIT.

Pitchik, C. and Schotter, A. (1988) Perfect equilibria in budget-constrained sequential auctions: An experimental study, Rand Journal of Economics 19(3), 363-388.

Rey, P. (2003) Toward a theory of competition policy, in Mathias Dewatripont, Lars Peter Hansen and Stephen J. Turnovsky (eds.), Advances in Economics and Econometrics, Theory and Applications, Eighth World Congress, Volume 2, Cambridge University Press.

Sade, O., Schnitzlein, C., and Zender, J. F. (2006) Competition and cooperation in divisible good auctions: An experimental examination, Review of Financial Studies 19, 195-235.

Schelling, T. (1960) The Strategy of Conflict, Harvard University Press, Cambridge, MA.

Sherstyuk, K. (1999) Collusion without conspiracy: An experimental study of one-sided auctions, Experimental Economics 2, 59-75.

Smith, J. L. and Levin, D. (2001) Entry coordination in auctions and social welfare: An experimental investigation, International Journal of Game Theory 30, 321-350.

Wang, J. J. D. and Zender, J. F. (2002) Auctioning divisible goods, Economic Theory 19, 673-705.

Wilson, R. (1979) Auctions of shares, Quarterly Journal of Economics 93, 675-698. 